\title{
Lens Capsule
}

National Cancer Institute

\section{Source}

National Cancer Institute. Lens Capsule. NCI Thesaurus. Code C32975.

A transparent, elastic membrane that encloses the lens of the eye. 